\title{
A randomized clinical trial of regional cerebral perfusion versus deep hypothermic circulatory arrest: Outcomes for infants with functional single ventricle
}

Caren S. Goldberg, MD, ${ }^{a}$ Edward L. Bove, MD, ${ }^{\mathrm{b}}$ Eric J. Devaney, MD, ${ }^{\mathrm{b}}$ Eileen Mollen, $\mathrm{PhD},{ }^{\mathrm{c}}$ Edward Schwartz, PhD, ${ }^{\mathrm{c}}$ Shauna Tindall, PhD, ${ }^{\mathrm{c}}$ Cheryl Nowak, RN, ${ }^{\mathrm{b}}$ John Charpie, MD, ${ }^{\mathrm{a}}$ Morton B. Brown, PhD, ${ }^{\mathrm{d}}$ Tom J. Kulik, MD, and Richard G. Ohye, MD

Supplemental material is available online.
From the Division of Pediatric Cardiology, Section of Cardiac Surgery, ${ }^{\mathrm{b}}$ Division of Pediatric Psychology, ${ }^{\mathrm{c}}$ and the School of Public Health, Department of Biostatistics, ${ }^{\mathrm{d}}$ University of Michigan, Ann Arbor, Mich.

Funded by the Doris Duke Charitable Foundation, University of Michigan General Clinical Research Center.

Read at the Eighty-sixth Annual Meeting of The American Association for Thoracic Surgery, Philadelphia, Pa, April 29-May 3, 2006.

Received for publication June 20, 2006; revisions received Nov 8, 2006; accepted for publication Nov 20, 2006.

Address for reprints: Caren S. Goldberg, MD, C.S. Mott Children's Hospital, L1221 Women's Box 0204, 1500 East Medical Center Dr, Ann Arbor, MI 48109-0204 (E-mail: cgoldber@umich.edu).

J Thorac Cardiovasc Surg 2007;133:880-7

$0022-5223 / \$ 32.00$

Copyright $\odot 2007$ by The American Association for Thoracic Surgery

doi:10.1016/j.jtcvs.2006.11.029
Objective: Regional cerebral perfusion has been adopted as a means to improve neuroprotection during aortic arch reconstruction. The purpose of this study was to determine whether a strategy of regional cerebral perfusion rather than one of deep hypothermic circulatory arrest during aortic arch reconstruction would improve neurodevelopment without increasing morbidity or mortality for patients undergoing the Norwood operation.

Methods: A randomized trial was performed in infants with single ventricle anatomy undergoing the Norwood operation. Participants were randomized to deep hypothermic circulatory arrest or regional cerebral perfusion. Neurodevelopment was measured before second-stage surgery and at 1 year by the Bayley Scales of Infant Development-II, Psychomotor Development Index and Mental Development Index. Intent-to-treat analysis was performed.

Results: Seventy-seven patients were enrolled. Survival to hospital discharge was $88 \%$ and to 1-year follow-up, $75 \%$, without a significant difference between groups. For the entire cohort, the mean (SD) psychomotor development index score was 77 (20) and the mean mental development index score was 92 (21), with psychomotor development index lower than mental development index both before second-stage surgery $(P<.0001)$ and at 1 year $(P<.0001)$. There were no statistical differences in mental development or psychomotor development scores between the groups at pre-second-stage operation or 1-year follow-up, although the point estimates were consistently lower for the regional cerebral perfusion group.

Conclusion: Infant development is delayed after the Norwood operation. Pilot data do not suggest that regional cerebral perfusion improves infant development. Further study with a multicenter clinical trial is imperative to address this important question.

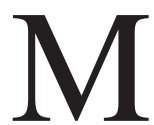
ajor advances in surgical techniques, medical management, and perioperative care have resulted in marked improvements in survival rates for children with hypoplastic left heart syndrome (HLHS). Although survival rates have improved, ${ }^{1-4}$ associated morbidities remain significant. Neurodevelopmental outcomes are among the major concerns. Multiple studies in the past decade have demonstrated that although children with complex congenital heart diseases, including HLHS, can have good neurodevelopmental outcomes, these children are at increased risk for neurologic abnormalities and developmental delay. ${ }^{5-9}$ Multiple factors including preoperative presentation, associated syndromes, and postoperative instability are likely to contribute to the risk of neurologic abnormalities. The use of deep hypothermic circulatory arrest (DHCA) is among the factors understood to negatively affect neurodevelopment. 

Abbreviations and Acronyms
BSID-II = Bayley Scales of Infant Development II
DHCA $=$ deep hypothermic circulatory arrest
HLHS = hypoplastic left heart syndrome
MDI = Mental Development Index
PDI = Psychomotor Development Index
$\mathrm{RCP}=$ regional cerebral perfusion

For infants undergoing the Norwood operation, DHCA has been the standard intraoperative perfusion technique used during aortic arch reconstruction. Circulatory arrest allows for a bloodless field and diminishes the risk of embolism. Deep hypothermia at nasopharyngeal temperatures of $18^{\circ} \mathrm{C}$ is used to lower the metabolic needs of the brain. However, despite this technique, the use of circulatory arrest has been associated with neurologic and developmental abnormalities. ${ }^{10-12}$

In an effort to protect the brain, regional cerebral perfusion (RCP) has been adopted by some centers as an alternative to DHCA. RCP is performed by cooling the patient as with DHCA. Through a polytetrafluoroethylene graft anastomosed to the innominate artery, blood can then be directed to the cerebral circulation. Flow rates of $20 \mathrm{~mL} \cdot \mathrm{kg}^{-1}$. $\min ^{-1}$ are generally used. RCP has been demonstrated to be technically feasible, ${ }^{13-15}$ but no randomized prospective study has compared functional neurodevelopmental outcomes for children undergoing the Norwood operation with the use of RCP with those after the Norwood operation with DHCA. The purpose of this study was therefore to determine whether the use of RCP rather than DHCA during aortic arch reconstruction in infants with HLHS and other functional single ventricle malformations is associated with improved neurodevelopment without increasing morbidity or mortality.

\section{Materials and Methods Enrollment Criteria}

A randomized controlled clinical trial was conducted at the University of Michigan Congenital Heart Center. Participants were enrolled from October 2001 through February 2005. Study inclusion required that the participants be born with HLHS or another single ventricle malformation requiring aortic arch reconstruction and that they be less then 30 days of age at the time of the Norwood operation. Patients were excluded from recruitment if the birth weight was less than $2 \mathrm{~kg}$, gestational age was less than 32 weeks, if there was an identified genetic syndrome known to be associated with abnormal neurodevelopment, or if there was a known history of maternal substance abuse. Guidelines of the institutional review board were followed and informed consent was obtained from the parents of all study participants.

\section{Stratification and Randomization}

Study participants were stratified by surgeon and by risk group. (Three congenital heart surgeons participated in this study). Patients with pulmonary venous obstruction, patients less then 36 weeks' gestation and/or less than $2.5 \mathrm{~kg}$, and patients with clinical shock or clinical seizures preoperatively were randomized within the higher risk strata. Within strata, randomization used block randomization with random block size.

Of note, although it was obviously not possible to blind the surgeon and the surgical team, the family and the other research team members, including the pediatric psychologists, were masked to the assigned technique.

\section{Surgical Technique}

Standard technique at the University of Michigan Congenital Heart Center at the time of this study was to perform a modified Norwood operation with a modified Blalock-Taussig shunt as previously described by our group. ${ }^{16}$ DHCA involved active cooling during cardiopulmonary bypass to less than $18^{\circ} \mathrm{C}$ by nasopharyngeal temperature probe over a period of greater than 20 minutes. Topical cooling was also used by applying ice bags to the patient's head.

All patients were managed throughout bypass with alpha-stat monitoring and underwent 10 minutes of modified ultrafiltration at the conclusion of bypass. Hematocrit was maintained at a target of $30 \%$ during bypass, with higher values at separation from bypass to achieve a post-modified ultrafiltration value in the mid to high 40 s.

For participants randomized to $\mathrm{RCP}$, at the time of the aortic arch reconstruction, the patient's body and head were cooled to $18^{\circ} \mathrm{C}$, as with DHCA. The proximal end of the Blalock-Taussig shunt was anastomosed at the distal innominate artery. The arterial bypass cannula was placed into the Blalock-Taussig shunt and $\mathrm{RCP}$ initiated at $5 \mathrm{~mL} \cdot \mathrm{kg}^{-1} \cdot \mathrm{min}^{-1}$, gradually increasing to 20 $\mathrm{mL} \cdot \mathrm{kg}^{-1} \cdot \mathrm{min}^{-1}$ (Figure 1). Near-infrared spectroscopy (INVOS 5100A; Somanetics, Troy, Mich) was used to measure cerebral oxygenation. At the conclusion of the arch reconstruction, the patient was returned to cardiopulmonary bypass and rewarmed, as with the standard technique.

\section{Demographic Data}

Demographic data including prenatal diagnosis, gestational age, birth weight, and anatomy were collected before stratification and randomization. At the time of neurodevelopmental assessment, information related to socioeconomic status was collected. The Hollingshead Four Factor Index was used to quantify socioeconomic status based on parental education and employment, on a scale from 8 (lowest socioeconomic level) to 66 (highest socioeconomic level).*

\section{Outcome Measurements}

Measures of safety. Safety information was collected in multiple ways. Each day while the patient was in the hospital, a member of the study team rounded on that patient to collect any information relating to morbidities. In addition, each family was contacted by telephone before the second-stage operation and

*Hollingshead AB. Four-factor index of social status. Unpublished manuscript, Yale University, Department of Sociology, New Haven [CT]. 1975. 


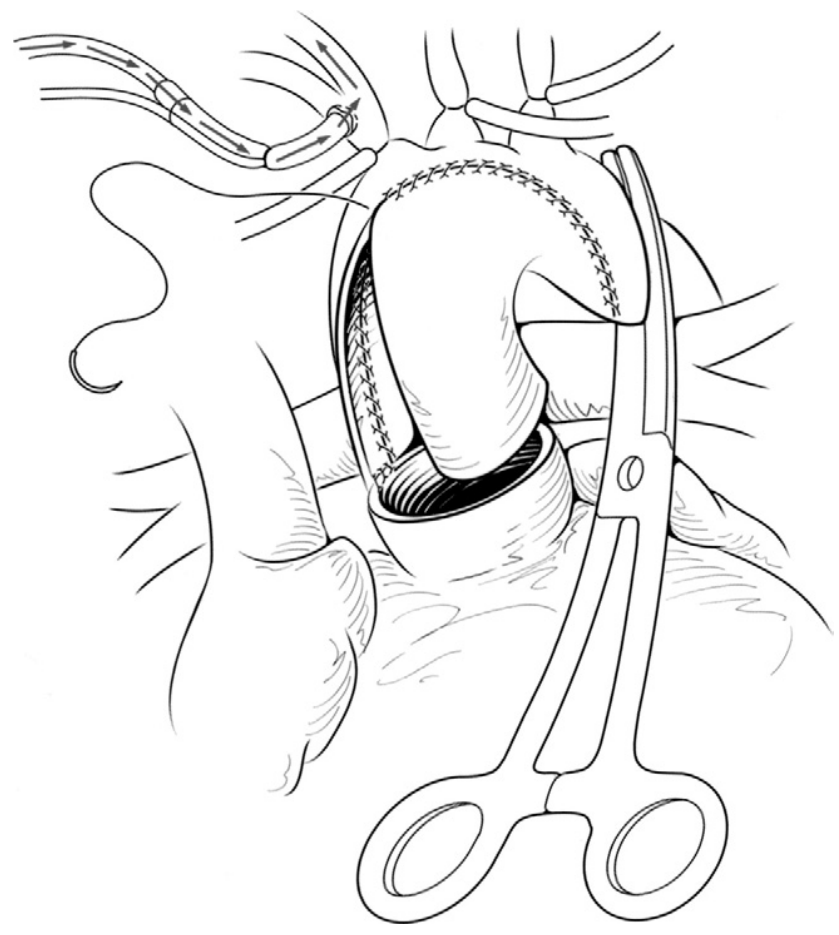

Figure 1. Ilustration of RCP. Arrows represent flow of blood from cardiopulmonary bypass circuit through polytetrafluoroethylene graft anastomosed to the innominate artery. $R C P$, regional cerebral perfusion.

again at 10 months of age. During all hospitalizations, including at the time of the second-stage operation, the patients were tracked as well. Echocardiograms and catheterizations are performed routinely as part of the clinical practice at the University of Michigan Congenital Heart Center before the second-stage procedure. The echocardiographic data were reviewed at hospital discharge after the Norwood operation and before the second stage to assess diaphragm function. Catheterization data before the second stage were used to determine the presence of aortic recoarctation. Need for cardiopulmonary resuscitation, need for extracorporeal membrane oxygenation, cardiac transplantation, vocal cord paresis, and/or diaphragm paresis before the second-stage operation were noted.

All mortalities were categorized as follows: (1) death before discharge after the Norwood operation, (2) interstage death before the second-stage procedure, or (3) death after the second-stage procedure.

Measures of neurologic and developmental outcome. Infant development was measured before the second-stage operation and again at 1 year of age with the Bayley Scales of Infant Development II (BSID-II). The BSID-II was administered by one of three pediatric psychologists. (E.M., E.S., S.T.) The pediatric psychologists were masked to the perfusion technique assignment. The BSID-II includes two scales or indices, the Mental Development Index (MDI) and the Psychomotor Development Index (PDI). The MDI is used primarily to assess memory, habituation, problem solving, early receptive and expressive language, social skills, and early number concepts. The PDI measures primarily gross and fine motor functioning. The mean score for the general population for each index is 100 points with a standard deviation of 15 points. $^{17}$

Socioeconomic status was measured using the Hollingshead Four Factor Index of Social Status for all participants who returned for developmental assessment before the second stage and/or at 1 year.

\section{Statistical Analysis}

The primary method of analysis was based on intention-to-treat methods to compare those participants randomly assigned to RCP with participants randomly assigned to DHCA.

$\chi^{2}$ or Fisher exact analysis was used to compare the differences in dichotomous variables between treatment groups. All normally distributed variables, such as scores on the PDI and MDI, were compared between treatment groups by the Student $t$ test. Paired $t$ test was used to compare two continuous variables between two time points or on two indices, the MDI before second-stage operation to the MDI at 1 year, or the MDI to PDI. Regression modeling was performed to adjust for impact of demographic variables on the BSID II scores, such as fetal diagnosis and socioeconomic status.

\section{Results}

\section{Demographics of Participants}

Seventy-seven patients were enrolled in the study. Twentythree $(30 \%)$ were within the high-risk strata. Thirty-eight were randomized to DHCA and 39 to RCP. In the case of 1 patient who was randomized to $\mathrm{RCP}$, a very small right carotid artery was identified in the operating room, which was not thought to be amenable to placement of a modified Blalock-Taussig shunt. For this reason a central shunt was used and the aortic arch reconstruction was performed with the use of DHCA. Because of the intent-to-treat analysis, this patient was included in the RCP group for morbidity and mortality data. Unfortunately, this patient died before the second-stage operation and therefore is not included in the analysis of BSID-II scores.

Preoperative demographics showed no statistical difference in sex, gestational age, birth weight, or cardiac anatomy. Socioeconomic status measured with the Hollingshead Four Factor Index was not different between groups for the participants who returned for developmental follow-up. All participants had a single ventricle and required a Norwood operation. The majority of the participants had HLHS (67/ $77) ; 32$ (84\%) of 38 in the DHCA treatment group and 35 (90\%) of 39 in the RCP treatment group. Overall, the diagnosis was made by prenatal ultrasound in $77 \%$ of the participants. A fetal diagnosis was made in $66 \%$ of patients randomly assigned to DHCA and $85 \%$ of those randomly assigned to $\mathrm{RCP}(P=.06)$. Thirty percent of the study cohort were within the high-risk strata, $31 \%$ of the RCP group and $29 \%$ of the DHCA group $(P=.86)$ (Table 1$)$. 
TABLE 1. Demographics: RCP versus DHCA subgroups

\begin{tabular}{lccc}
\hline & $\begin{array}{c}\text { RCP }(\mathbf{n}, \%): \\
\mathbf{N}=\mathbf{3 9}\end{array}$ & $\begin{array}{c}\text { DHCA: } \\
\mathbf{N}=\mathbf{3 8}\end{array}$ & $\begin{array}{c}\boldsymbol{P} \\
\text { value }\end{array}$ \\
\hline Male gender (n, \%) & $26(67 \%)$ & $28(74 \%)$ & .50 \\
Fetal diagnosis (n, \%) & $33(85 \%)$ & $25(66 \%)$ & .06 \\
HLHS (n, \%) & $35(90 \%)$ & $32(84 \%)$ & .26 \\
High-risk group (n, \%) & $12(31 \%)$ & $11(29 \%)$ & .86 \\
$\begin{array}{l}\text { Gestational age, wk } \\
\quad \text { (mean } \pm \text { SD) }\end{array}$ & $38.4 \pm 2.1$ & $39.9 \pm 1.1$ & .11 \\
Birth weight, kg (mean \pm SD) & $3.4 \pm .43$ & $3.4 \pm .44$ & .63 \\
$\begin{array}{l}\text { Socioeconomic status } \\
\quad \text { (mean } \pm \text { SD) }\end{array}$ & $43.4 \pm 11.5$ & $39.8 \pm 14.7$ & .33 \\
\hline
\end{tabular}

$\overline{R C P}$, Retrograde cerebral perfusion; $D H C A$, deep hypothermic circulatory arrest; $H L H S$, hypoplastic left heart syndrome; $S D$, standard deviation.

\section{Surgical Parameters}

Comparison of cardiopulmonary bypass and crossclamp times demonstrate that the patients assigned to RCP tended to have a longer cardiopulmonary bypass time $(129.2 \pm 57$ vs $106.9 \pm 49$ minutes; $P=.07)$ and had a longer crossclamp time $(48.7 \pm 12$ vs $42.1 \pm 11$ minutes; $P=.01)$. There were 3 patients randomized to RCP who required DHCA for a significant portion of the aortic arch reconstruction. However, even when these patients are removed from the analysis, the patients randomized to RCP received an average of 5.7 minutes of DHCA, resulting in a longer crossclamp time (50 vs 42 minutes; $P=.03$ ). This period of DHCA is required for the delivery of cardioplegic solution through the arterial cannula and for repositioning of the arterial cannula into the Blalock-Taussig shunt for RCP. In addition, with exclusion of the patients randomized to RCP who received a prolonged period of DHCA, cardiopulmonary bypass time was longer for the RCP group (130.8 vs 105.9 minutes; $P=.04$ ). For the group with a primary strategy of RCP, the mean RCP time was $41.1 \pm 9.0$ minutes. The mean DHCA time for the group randomized to DHCA was $41.0 \pm 10$.

\section{Survival}

Overall hospital survival for the study cohort was $88 \%$. There were 3 predischarge deaths in the RCP subgroup $(8 \%)$ and 6 predischarge deaths in the DHCA subgroup $(16 \%)(P=.31)$. After discharge, but before the secondstage operation, 8 patients died from the RCP group $(8 / 36$, $22 \%)$ and 2 from the DHCA subgroup $(2 / 32,6 \%), P=.08$. At 1 year, survival was $75 \%$ for the entire cohort, $69 \%$ for the RCP group, and $79 \%$ for the DHCA group $(P=.33)$ (Figure 2).

\section{Other Safety Outcomes}

There was no statistically significant difference between the two groups for other safety outcomes including the incidence of cardiac arrest, need for extracorporeal membrane

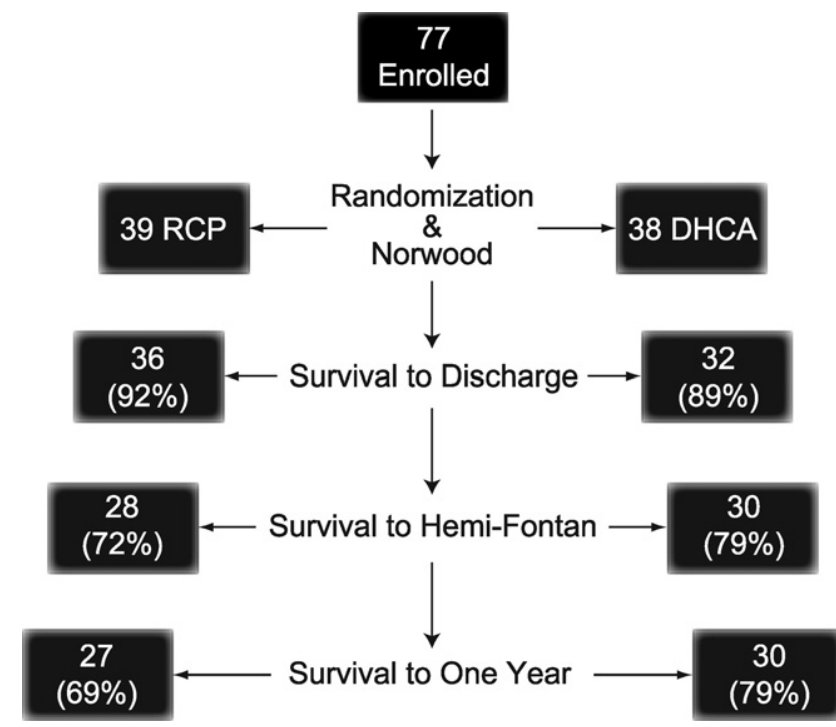

Figure 2. Survival for the RCP and DHCA treatment groups at hospital discharge after Norwood operation, to second-stage operation, and to 1 year of age. $R C P$, retrograde cerebral perfusion; DHCA, deep hypothermic circulatory arrest.

oxygenation, incidence of shunt malfunction, diaphragm paresis, or evidence of vocal cord paresis before the secondstage operation (Table 2). Three patients were found to have recoarctation of the aorta, which required intervention either surgically or via cardiac catheterization. All 3 of these patients were in the RCP subgroup. Three patients required cardiac transplantation over their first year of life. All 3 of these patients were in the RCP subgroup as well (Table 2).

\section{Developmental Outcomes}

The BSID-II was performed before the second-stage operation in 52 patients, and in 50 patients at 1 year of age. The median age at 1-year follow-up was 12 months. There were 6 patients who returned for follow-up after 13 months of age. There was no significant difference or apparent bias in the scores of this subgroup compared with the 44 partic-

TABLE 2. Morbidity incidences: RCP versus DHCA subgroups

\begin{tabular}{lccc}
\hline & RCP $(\mathbf{n}, \%)$ & DHCA $(\mathbf{n}, \%)$ & $\boldsymbol{P}$ value \\
\hline Cardiac arrest & $6(15 \%)$ & $7(18 \%)$ & .72 \\
ECM0 & $5(13 \%)$ & $8(21 \%)$ & .34 \\
Diaphragm paresis & $3(7.7 \%)$ & $2(5.3 \%)$ & .99 \\
Vocal cord paresis & $1(2.6 \%)$ & $2(5.3 \%)$ & .62 \\
Recoarctation & $3(7.7 \%)$ & $0(0 \%)$ & .24 \\
Shunt redo & $5(13 \%)$ & $4(10.5 \%)$ & .75 \\
Heart transplantation & $3(7.7 \%)$ & $0(0 \%)$ & .24 \\
\hline
\end{tabular}

$R C P$, Retrograde cerebral perfusion; $D H C A$, deep hypothermic circulatory arrest; ECMO, extracorporeal membrane oxygenation. 
A. Comparison of MDI to PDI
Prior to Second Stage Operation

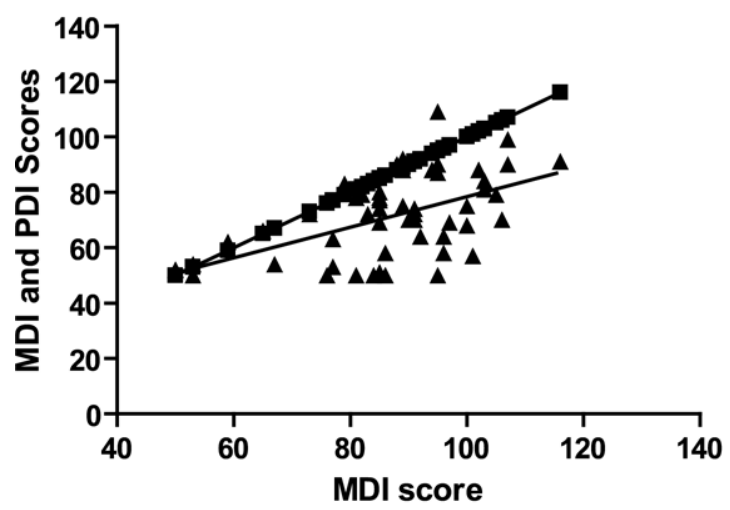

B. Comparison of MDI to PDI at One Year

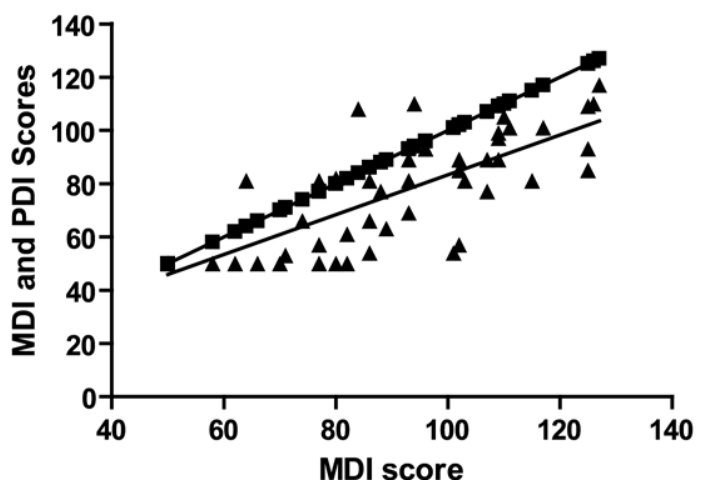

Figure 3. PDI and MDI scores are plotted on the y-axis compared with MDI scores on the $x$-axis at pre-second stage $(A)$ and at 1 year (B). PDI, Psychomotor Development Index; MDI, Mental Development Index.

ipants who returned during the study designated window (12 \pm 1 months). Given this finding, the summary and comparison data include these participants.

Before the second-stage operation, the mean (SD) MDI and PDI scores for the entire cohort were 87.4 (14) and 71.5 (15), respectively. There was a tendency toward higher scores for the entire study group at 1 year, 91.8 (21) and 77.1 (21) for the MDI $(P=.21)$ and PDI $(P=.07)$, respectively. The MDI scores were significantly higher than the PDI scores both before the second-stage $(P<.0001)$ operation and at 1 year $(P<.0001)$ (Figure 3$)$.

The group randomized to RCP had a lower average point estimate for the PDI and MDI compared with the point estimates for the DHCA treatment group on these indices at both pre-second stage and 1-year evaluations. There was wide variation, however, and the differences were not statistically significant (Figure E1 and Table 3). Only 1 of the 50 patients who returned for 1-year follow-up required a
TABLE 3. Bayley Scales of Infant Development results; A comparison of RCP and DHCA groups

\begin{tabular}{|c|c|c|c|}
\hline & RCP & DHCA & $P$ value \\
\hline $\begin{array}{l}\text { PDI before } \\
\text { 2nd stage }\end{array}$ & $67.3 \pm 13.8(n=23)$ & $74.8 \pm 15.0(n=29)$ & .07 \\
\hline $\begin{array}{l}\text { MDI before } \\
\text { 2nd stage }\end{array}$ & $85.6 \pm 15.4(n=23)$ & $88.9 \pm 13.3(n=29)$ & .41 \\
\hline PDI YR & $74.0 \pm 20.3(n=22)$ & $79.6 \pm 20.9(n=28)$ & .34 \\
\hline MDI YR & $88.9 \pm 21.6(n=22)$ & $94.1 \pm 20.0(n=28)$ & .39 \\
\hline
\end{tabular}

change from RCP to DHCA strategies during the Norwood operation for a significant portion of the aortic arch reconstruction. The analysis was not affected significantly when the data from this participant were excluded.

BSID-II scores were compared between those participants with a fetal diagnosis and those without a prenatal diagnosis. Fetal diagnosis was associated with higher scores on the MDI before the hemi-Fontan procedure; the mean MDI for the group with a fetal diagnosis was 89.9 compared with 81.3 for the nonfetal group $(P=.04)$. However, there was no statistical difference in the PDI before the second stage or in the MDI or PDI at 1 year.

Models including fetal diagnosis and socioeconomic status were created to determine whether adjustment for these factors would provide a different understanding of the impact of RCP on MDI and PDI scores at the pre-second-stage and 1-year evaluations. The magnitude of the differences between groups was unchanged.

\section{Discussion}

In recent years, multiple centers have evaluated neurocognitive outcomes of children with HLHS and other single ventricle anomalies. Although individual patients can have normal development, studies consistently demonstrate that these patients are at an increased risk for developmental abnormalities. ${ }^{5-9}$ It is widely understood that the etiology of the neurologic deficits in this patient group are multifactorial. The use of DHCA is among the modifiable factors thought to increase the risk of neurocognitive abnormalities in children with complex congenital heart abnormalities. For this reason, alternatives to DHCA, including RCP, have recently garnered attention.

Myung and colleagues ${ }^{18}$ compared the impact of RCP to DHCA on neurologic function in a fetal pig model. Fetal pigs were randomized to a 90-minute period of either RCP or DHCA. The authors found that postoperative neurobehavioral scores were more likely to be abnormal in the DHCA group than in the RCP group and that the RCP subgroup had less evidence of apoptosis on autopsy. How- 
ever, there have been no data demonstrating improved outcomes with the use of RCP in infants.

Dent and colleagues ${ }^{19}$ from the University of Cincinnati have performed head magnetic resonance imaging studies of children with HLHS preoperatively and after the Norwood operation to determine whether RCP protects against hypoxic-ischemic injury evident structurally. Head magnetic resonance imaging was performed before the Norwood operation and during the early postoperative period in 15 newborn infants, all of whom had aortic arch reconstruction performed with the use of RCP. The investigators found that $73 \%$ of study participants had worsened or new evidence of cerebral ischemia after the Norwood operation despite the use of RCP during aortic arch reconstruction. ${ }^{19}$ There was no direct control group in this study and the RCP time averaged 83 minutes, significantly longer than the 41 minutes of DHCA time that Wypij and colleagues ${ }^{20}$ found to be relatively safe.

The primary aim of this study was to investigate the hypothesis that RCP would improve neurodevelopmental outcomes without significantly affecting morbidity and mortality. We have studied too few patients thus far to draw definitive conclusions regarding the impact of RCP rather than DHCA on neurodevelopmental outcome on survival for children undergoing Norwood palliation. However, our data do not support the hypothesis that RCP improves neurodevelopmental outcomes. Since its initial description, $\mathrm{RCP}$ has been adopted by surgeons at some congenital heart centers with the belief that cerebral perfusion will provide better protection of the brain than DHCA.

Although we measured no statistical difference in morbidity and mortality outcomes between the two treatment groups, we could not demonstrate any beneficial effect of RCP on neurodevelopment.

This study was stratified for a composite high-risk group and for surgeon. Fetal diagnosis was not stratified and was somewhat different between the two groups. Mahle and colleagues $^{21}$ have found that fetal diagnosis is associated with lower rates of neurologic events in patients with HLHS. In this study there was a higher rate of fetal diagnosis in the RCP subgroup. This may be expected to bias the RCP group to improved neurodevelopment. Adjustment for fetal diagnosis was therefore performed with regression modeling, but although the tendency was for improved scores in patients with a fetal diagnosis, the difference between the RCP and DHCA treatment groups was not found to be statistically different.

There are a number of limitations to our study. Whereas the exposure to DHCA or RCP occurs during the newborn period at the Norwood operation, the primary outcome measure was performed at 1 year of age. Thus, all participants underwent a second-stage operation, before the 1-year BSID-II evaluation. It was for this reason that the BSID-II was administered before the second stage as well. It is interesting to note that many of the participants had higher scores on the BSID-II at 1 year than at the pre-second-stage evaluation, suggesting that the second stage is not typically associated with new neurologic insults. By the 1-year follow-up, more time generally has passed since the last hospitalization and thus the patient has potentially had more time to progress developmentally. Longer-term follow-up will be important to discern if developmental catch-up will be more likely to occur in either the RCP or DHCA treatment groups.

This study is also limited by the relatively small sample size. When the findings of a planned early look at the data were analyzed, the estimated required sample size to address the study hypothesis was substantially increased and it was determined that a multicenter study would be more appropriate to address this question efficiently. However, although the sample size is relatively small, there was a consistent trend for the RCP treatment group to have lower developmental scores.

As with all trials comparing a new technique with a standard technique, this study is subject to a learning curve bias. Although RCP was used at our center selectively for approximately 1 year before the initiation of this trial, we recognize that this is still limited experience compared with the experience with DHCA at our center. To further investigate for evidence of a developing learning curve, we have analyzed the total bypass time for patients randomized to $\mathrm{RCP}$ over time and find that there is no change in bypass time over the study period (data not shown).

Finally, the method of RCP used in this study was based on the published experience at the time this trial was developed. Since that time, the method of RCP delivery has evolved at some centers. We do recognize that this study has only tested a single method of providing RCP and that there may be variations that would lead to different results.

The data from this trial do demonstrate that mental and psychomotor development as measured by the BSID-II is delayed in infants after the Norwood operation. These data also demonstrate significantly lower scores on the PDI than on the MDI, as previously shown. ${ }^{22,23}$ The reason for this result remains unclear, although the finding is consistently reproducible and likely represents a predisposition for particular areas of central nervous system insult.

\section{Conclusions}

Consistent with the findings of others, these data demonstrate that development in children with HLHS and other related single ventricle malformations is delayed, with lower scores on the PDI than on the MDI. RCP was not associated with improved neurodevelopmental outcomes when compared with DHCA. Although this was a randomized controlled clinical trial, the sample size was limited and 
these pilot data are unfortunately inconclusive. As centers have adopted the RCP technique as a standard of care, these data support the need for a multicenter randomized clinical trial to compare safety and neurodevelopmental outcomes of RCP with those of DHCA before broad institutionalization on RCP.

\section{References}

1. Mahle WT, Spray TL, Wernovsky G, Gaynor JW, Clark BJ 3rd. Survival after reconstructive surgery for hypoplastic left heart syndrome: a 15 year experience from a single institution. Circulation. 2000;102(19 suppl 3):III136-41.

2. Bove EL, Lloyd TR. Staged reconstruction for hypoplastic left heart syndrome. Contemporary results. Ann Surg. 1996;224:387-94.

3. Tweddell JS Hoffman GM, Mussatto KA, Fedderly RT, Berger S, Jaquiss RD, et al. Improved survival of patients undergoing palliation of hypoplastic left heart syndrome: lessons learned from 115 consecutive patients. Circulation. 2002;106(suppl I):I82-9.

4. Kern JH, Hayes JH, Michler RE, Gersony WM, Quagebeur JM. Survival and risk factor analysis for the Norwood procedure for hypoplastic left heart syndrome. Am J Cardiol. 1997;80:170-4.

5. Goldberg CS, Schwartz EM, Brunberg JA, Mosca RS, Bove EL, Schork MA, et al. Neurodevelopmental outcome of patients after the Fontan operation: a comparison between children with hypoplastic left heart syndrome and other functional single ventricle lesions. J Pediatr. 2000; 137:646-52.

6. Mahle WT, Clancy RR, Moss EM, Gerdes M, Jobes DR, Wernovsky G. Neurodevelopmental outcome and lifestyle assessment in schoolaged and adolescent children with hypoplastic left heart syndrome. Pediatrics. 2000;105:1082-9.

7. Kern JH, Hinton VJ, Nereo NE, Hayes CJ, Gersony WM. Early developmental outcome after the Norwood procedure for hypoplastic left heart syndrome. Pediatrics 1998;102:1148-52.

8. Wernovsky G, Stiles KM, Gauvreau K, Gentles TL, duPlessis AJ, Bellinger DC, et al. Cognitive development after the Fontan operation. Circulation. 2000;102:883-9.

9. Uzark K, Lincoln A, Lamberti JJ, Mainwaring RD, Spicer RL, Moore JW. Neurdevelopmental outcomes in children with Fontan repair of functional single ventricle. Pediatrics. 1998;101:630-3.

10. Oates RK, Simpson JM, Turnbull JAB, Cartmill TB. The relationship between intelligence and duration of circulatory arrest with deep hypothermia. J Thorac Cardiovasc Surg. 1995;110:786-92.

11. Newburger JW, Jonas RA, Wernovsky G, Wypij D, Hickey PR, Kuban $\mathrm{KC}$, et al. A comparison of perioperative neurologic effects of hypothermic circulatory arrest versus low flow cardiopulmonary bypass in infant heart surgery. N Engl J Med. 1993;329:1057-64.

12. Bellinger DC, Wypij D, Kuban KC, Rappaport LA, Hickey PR, Wernovsky G, et al. Developmental and neurological status of children at 4 years of age after heart surgery with hypothermic circulatory arrest or low-flow cardiopulmonary bypass. Circulation. 1999;100:526-32.

13. Pigula FA, Nemoto EM, Griffith BP, Siewers RD. Regional low-flow perfusion provides cerebral circulatory support during neonatal aortic arch reconstruction. J Thorac Cardiovasc Surg. 2000;119:331-9.

14. Asou T, Kado H, Imoto Y, Shiokawa Y, Tominaga R, Kawachi Y, et al. Selective cerebral perfusion technique during aortic arch repair in neonates. Ann Thorac Surg. 1996;61:1546-8.

15. Tchervenkov CI, Chu VF, Shum-Tim D, Laliberte E, Reyes TU. Norwood operation without circulatory arrest: a new surgical technique. Ann Thorac Surg. 2000;70:1730-3.

16. Bove EL. Current status of staged reconstruction for hypoplastic left heart syndrome. Pediatr Cardiol. 1998;19:308-15.

17. Bayley N. Bayley Scales of Infant Development. 2nd ed. San Antonio: Pychological Corp. 1993.

18. Myung RJ, Petko M, Judkins AR, Schears G, Ittenbach RF, Waibel RJ, et al. Regioanl low-flow perfusion improves neurologic outcome compared with deep hypothermic circulatory arrest in neonatal piglets. J Thorac Cardiovasc Surg. 2004;127:1051-7.
19. Dent CL, Spaeth JP, Jones BV, Schwartz SM, Glauser TA, Hallinan B, et al. Brain magnetic resonance imaging abnormalities after the Norwood procedure using regional cerebral perfusion. $J$ Thorac Cardiovasc Surg. 2006;131:190-7.

20. Wypij D, Newburger JW, Rappaport LA, duPlessis AJ, Jonas RA, Wernovsky G, et al. The effect of duration of deep hypothermic circulatory arrest in infant heart surgery on late neurodevelopment: the Boston Circulatory Arrest Trial. J Thorac Cardiovasc Surg. 2003;126: 1397-403.

21. Mahle WT, Clancy RR, McGaurn SP, Goin JE, Clark BJ. Impact of prenatal diagnosis on survival and early neurologic morbidity in neonates with hypoplastic left heart syndrome. Pediatrics. 2001;107: 1277-82.

22. Gaynor JW, Gerdes M, Zackai EH, Bernbaum J, Wernovsky G, Clancy RR, et al. Apolipoprotein E genotype and neurodevelopmental sequelae of infant cardiac surgery. J Thorac Cardiovasc Surg. 2003; 126:1736-45.

23. Jonas RA, Wypij D, Roth SJ, Bellinger DC, Visconti KJ, du Plessis $\mathrm{AJ}$, et al. The influence of hemodilution on outcome after hypothermic cardiopulmonary bypass: results of a randomized trial in infants. J Thorac Cardiovasc Surg. 2003;126:1765-74.

\section{Discussion}

Dr Frank L. Hanley (San Francisco, Calif). Thank you. I have no conflicts.

I congratulate Dr Goldberg and her colleagues for a very timely study and for an excellent manuscript and presentation. Sorting out the relative neurodevelopmental morbidity of DHCA and continuous cardiopulmonary bypass in neonatal heart surgery is a major challenge. As the authors imply, this is almost impossible to achieve in a single-institution study. An important contribution of this study, however, is that it may act as a catalyst for further thought and possibly for multi-institutional analysis. I have two comments to make and then a couple of brief questions, and I hope you can bear with me. Most of them relate to technique because technique is so important in neurodevelopmental outcome in terms of what we do in the operating room as we are learning more and more.

The first comment relates to some very detailed technique issues. I hesitate to dwell on these in this forum, but I believe they are important. There are many ways to do RCP, and the details of how it is done can affect the likelihood of neural injury. The technique used in this study, using a polytetrafluoroethylene graft, which is cannulated for RCP, requires a number of minutes of little or no innominate artery perfusion during which the actual graft is being attached onto the innominate artery. In addition, the technique requires, at least as I understand it, several periods of DHCA, one when the central cannula is transferred into the graft, one when the cannula is brought back to its central position after most of the operation is done, and then when the cardioplegic solution is given, because it is given through that same cannula. So this involves three separate periods of circulatory arrest. Furthermore, as you mentioned, there is another obligatory period of very low unphysiologic flow, $5 \mathrm{~mL} \cdot \mathrm{kg}^{-1} \cdot \mathrm{min}^{-1}$, for some undisclosed period of time. As a result, all RCP patients received a period of circulatory arrest that was significant, a mean of 9 minutes overall in three separate settings, in addition to some unphysiologic flow. How much of this morbidity is found in this RCP group and how it is related to these factors is actually impossible to tell. So that is a major question that will have to be answered over time.

As a point of contrast, another way to perform RCP is to directly cannulate the innominate artery with the arterial cannula at the beginning of the case and to use that throughout. There is no switching or further manipulation of the cannula, no periods of 
deliberate unphysiologic low cerebral blood flow, and no periods of circulatory arrest. Cardioplegic solution is delivered directly into the ascending aorta by a separate cannula and angiocath.

The point I am trying to make is not that one is better than the other. We do not know, and I am sure anyone can make an argument that this technique has certain disadvantages as well. However, designing an effective multicenter study and really trying to understand this is going to be a major challenge.

The second comment relates to the maturity of the two techniques. DHCA techniques have been widely used and fine tuned over many decades. RCP has been used much less widely and for much shorter periods of time. Time and experience have made and inevitably will continue to make both techniques safer, but with DHCA we will never get away from the fact that the brain is being starved of nutrients the second the pump is turned off. RCP has not had the benefit of nearly the amount of experience or fine tuning that DHCA has had, and furthermore, its problems and current limitations are easily understood and much more solvable than figuring out how to make the brain happy when there is no blood flow going to it. We are not even close to identifying the ideal way to do RCP at this point in time.

This comment is meant to be general, but it also applies directly to the study. My understanding of the standard technique at the University of Michigan is that DHCA has been used for quite a long time, many decades. So it is a good bet that the authors have pitted their RCP learning curve against their decades long, finely tuned circulatory arrest technique in this study. For all of these reasons, the long-term bet may well be on RCP, but we certainly do not know.

I would invite your responses to those two general comments, and then I have two specific questions.

Why did you use $18^{\circ} \mathrm{C}$ as your level of hypothermia when there is continuous perfusion? At this level, both the warming and cooling times are substantially increased and therefore overall cardiopulmonary bypass may well be lengthened unnecessarily. This is another variable that certainly has not been worked out but may well need to be addressed. I am just wondering why you picked that same level of hypothermia.

The second question is also technical and it relates to venous cannulation. During your RCP did you use a single venous cannula, which can be cumbersome when you have continuous perfusion, or did you use bicaval cannulation with snares, and did you use a left ventricular vent? I hate to put you in this position because I know you are not a surgeon, but these issues are very important, both in terms of how long you are going to be on bypass, how well you can do the operation, and in terms of embolic phenomena. If you do not have a vent in place with a single venous cannula, you easily can capture air in the ventricle that cannot be removed, and this may have implications as well.

Dr Goldberg. Thank you very much, Dr Hanley, for those very pertinent points and excellent questions. As you commented, I am not a surgeon but I will try to address your questions. I know Dr Ohye and Dr Bove are in the room. Please feel free to interrupt me at any time.

To start off with your comments, this is a very difficult group to study. Patients with HLHS have multiple periods of time during their lives where they may have hemodynamic instability or be at risk for things that we think put them at risk for neurodevelopmental abnormalities. You stated that a multicenter study is necessary but would be a challenge. I agree that it will be a challenge for all the reasons you described, including that there are multiple technical issues that need to be resolved regarding the delivery of RCP.

You asked about the timing of DHCA in those patients randomized for RCP. For the patients who were able to continue with the RCP technique, excluding the 3 patients who required conversion to DHCA, the mean time of DHCA was about 7 minutes. There were, as you outlined, three separate brief periods of DHCA, the longest of which is approximately 3 minutes for the delivery of cardioplegic solution. However, I do not suspect that many would argue that a 3-minute period of DHCA would significantly affect neurodevelopmental outcome. There was a single cannula technique used as well.

Now, why use a temperature of $18^{\circ} \mathrm{C}$ ? The reason we decided to continue to cool the patients at $18^{\circ} \mathrm{C}$ was that if RCP needed to be abandoned, then DHCA could be instituted immediately without any delay. In addition, we had no proof that RCP was actually neuroprotective, and therefore we wanted to take all prudent measures to protect the central nervous system.

Dr Charles D. Fraser (Houston, Tex). Again, congratulations on a beautifully presented study and for bringing to light the importance of a multicenter trial to try and get at the truth about what many of us feel biased about. I wanted to also embellish on Dr Hanley's thoughts about the actual technique of the RCP.

You stated in your presentation that the perfusion flow rate was 20 $\mathrm{mL} \cdot \mathrm{kg}^{-1} \cdot \mathrm{min}^{-1}$, and a really important question then is how was that decided on and how are we confident that that is an adequate cerebral perfusion rate? In other words, how did you determine adequacy of cerebral perfusion during the bypass period?

Dr Goldberg. We decided on the technique early on when we started this study in 2001. When we designed this study, we based our flow rates on the prior studies and descriptions of RCP and data from animal models available at that time. I realize that different flow rates have been used in more recent literature. However, some authors caution that an increased flow rate may increase the risk of cerebral edema. In addition, we are not aware that there have been any studies to suggest that one flow rate is clearly superior to any other. There are all sorts of issues to consider, but we were consistent at aiming at $20 \mathrm{~mL} \cdot \mathrm{kg}^{-1} \cdot \mathrm{min}^{-1}$. The patients were monitored with cerebral oximetry, but in talking with the surgeons, they never needed to modify the flow rate based on the cerebral oximetry data with saturations on RCP maintained between 70 and 90 .

Dr Paul Kurlansky (Miami, Fla). This is not so much a clinical question as an experimental one. As an increasing amount of information is becoming available about the biochemistry of reperfusion injury, I was wondering whether you are aware of any studies in the laboratory, at least, if not clinically, to take the opportunity of the time period of ischemic arrest in the reperfusion model to supply substrates that might ameliorate the reperfusion injury that would occur necessarily at the time of complete reperfusion.

Dr Goldberg. Are you asking whether there are any treatments that can be used during RCP to ameliorate reperfusion injury?

Dr Kurlansky. Correct, similar to the sort of substrate enhancement approach to cardioplegia.

Dr Goldberg. I apologize. I do not know the answer to that question, whether there have been any medications or treatments or perfected cooling or a perfect temperature that would optimize RCP. 
A.

PDI at pre-Second Stage Operation

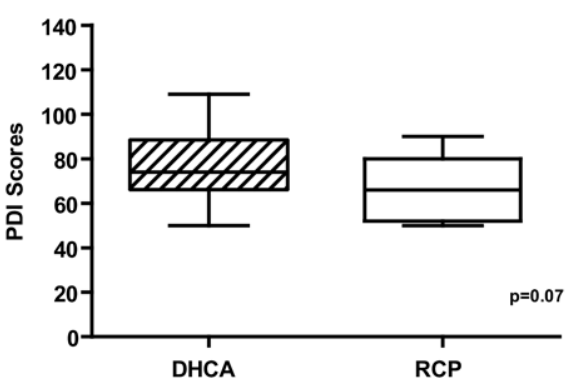

c.

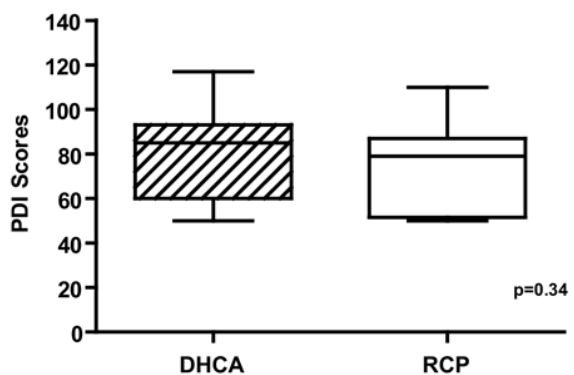

B.

MDI at Pre-Second Stage Operation

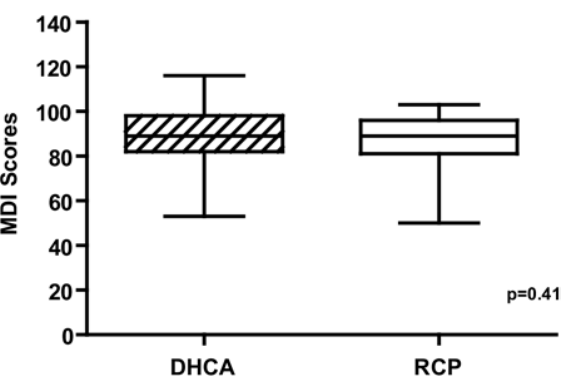

D.

MDI at One Year

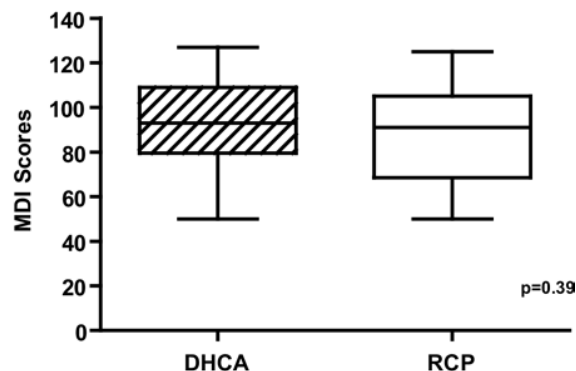

Figure E1. Box plots demonstrate comparison of DHCA and RCP groups for PDI pre-second stage (A), MDI pre-second stage (B), PDI at 1 year (C), and MDI at 1 year (D). DHCA, deep hypothermic circulatory arrest; $R C P$, regional cerebral perfusion; PDI, Psychomotor Development Index; MDI, Mental Development Index. 